\title{
LAS UTOPÍAS EN DON QUIJOTE
}

Hablar de utopias en don Quijote implica que las hay, aunque sean de signo contrario, y que tienen además una función que cumplir dentro de la narrativa de la obra.

Platón fue el primero en describir una utopía social en su obra La República '. Pero no acertó a darle el nombre que iba a identificar más adelante ese tipo de ensayo filosófico-literario. Platón creía tan firmemente en la viabilidad de su ciudadrepública que sin duda hubiera desechado con irritación la mera sugerencia que la República nunca iba a ser más que una organización política sobre el papel nada más: el pensador griego era demasiado metafísico para poderse plantear siquiera el problema.

Unos dos mil años más tarde iba a aparecer en escena el genio literario con una visión pragmática de la vida: Tomás Moro. Su obra, escrita en latín y publicada ya en $1518^{2}$, en la tercera edición es donde da el nombre al concepto según el rey de la isla Utopus. Es casi con irreverencia al gran filósofo griego que intentaremos definir el género por distintas categorias. La palabra utopía, utilizada en la obra de Moro por primera vez, tiene la

${ }^{1}$ Utilizamos para este estudio la edición de Richard W. Sterling, Canada Penguin Books, 1985. Para las demás obras de Platón, usamos la edición de Aguilar, Platón, obras completas, Madrid, 1979.

2 La mejor edición crítica que hemos podido ver es la de la colección Norton Critical Editions in the History of Ideas, Sir Thomas More Utopia, translated and edited by Robert M. Adams (New York, 1975). La Utopia de More se tradujo al alemán en 1524 y al italiano en 1548. Pero en ninguno de los dos países sirvió de semilla de futuras utopias. Puede verse la reunión de ponencias del Coloquio tenido en Bruselas en 1961, Travaux de l'institut l'humanisme, Les Utopias d la Renaissance, Bruselas-Paris, Presses Universitaires de Bruxelles et de France, 1963. 
raíz griega doble ou (no) topos (lugar). Es decir, un sitio que en realidad no existe; sólo se halla en la imaginación del que habla o escribe. Hay que distinguir entre utopía e idealismo. Ya en Platón se distingue muy claramente entre el idealismo, o la teoría de las ideas, y la descripción de una ciudad perfecta descrita en La República. Como derivaciones del concepto de utopía, valga aclarar los matices de Eutopía (eu = bueno) como buen lugar, lleno de bienes, donde sería apetecible nacer, crecer y morir. Este concepto eutópico, interpretado en el plano espiritual, se fundiría con la idea del cielo o paraíso, más o menos común a varias religiones ${ }^{3}$. Muy cercana a este sitio es la definición de utopía favorecida por George Kateb: "It would be posible to say that the absence of radical evil is the correct definition of Utopia and to go beyond that is to impose on the world, though with the best motives, a partial or eccentric vision of life" 4 .

Muy cercano a este concepto es el de eupsiquía, es decir el estado espiritual de felicidad completa o casi completa que se puede experimentar en ocasiones, aunque sea de corta duración.

Por último, mencionaré también la distopía (o cacotopía, según la raíz griega) en que se cumple lo opuesto de la eutopía. Es el conjunto de todo mal, o casi todo mal, posible acumulado en un mismo lugar. Como se ve, es el caso paralelo y opuesto del cielo.

En cuanto a la función que cumplen las diferentes formas de utopía, se podría afirmar que su común denominador es el efecto general de purgación de la realidad presente, un escape de la misma. A la vez trata también de presentar un modelo de perfección, social o personal, a la que se puede aspirar. En Don Quijote, los casos de utopía social son de este tipo: modelos de reforma y perfeccionamiento. Más adelante, después de la Revolución industrial, todo modelo utópico no podrá menos de incluir también el aspecto tecnológico. Vaya como ejemplo la pre-

${ }^{3}$ Dentro del cristianismo se suele definir el cielo como el lugar en que hay la acumulación de todo bien sin mal alguno. Esta duración constante de las utopías a través de la historia de la humanidad parece argüir en favor de la hipótesis de que tales creaciones imaginadas son una expresión perdurable del espíritu humano. Puede verse Roger Mucchielu, Le Mythe de la cité ideale, Paris, Presses Universitaires de France, 1961, pp. 7 y ss. Sobre la utopia religiosa hubo un Congreso en 1963 titulado Vom Sinn der Utopie, en que se trató de las raíces psicológicas y religiosas de la utopía: Eranos Jahrbuch, 1963, Zurich, Rhein-Verlag, 1964. MIRCEA ELIADE tiene una contribución a ese Congreso sobre «Paraiso y Utopía; Geografía Mítica y Escatológicaw.

GeORGE KATEB, «Utopia and the good life», Daedalus, vol. 94, 1965, n.॰ 2 , 454. Este número de la Revista está dedicado por completo al estudio de las utopías en la literatura. En este contexto merece especial mención la obra de Karl Mannheim, Ideología y Utopia, Traducción de E. Terrón, Madrid, Aguilar, 1966. 
dicción utópica que hace John MacNie en su obra The Diothas ${ }^{5}$, donde dice habrá un coche que correrá sin caballos a la velocidad de $30 \mathrm{~km}$. por hora (y hasta un poco más, cuesta abajo!).

En literatura, las distintas utopías se usan como instrumentos literarios: como cuadro descriptivo de amenidades, como poderoso látigo fustigador del estado opresivo como lo hace Yevgeny Zamyatin en su novela $W^{6}{ }^{6}$, como instrumento de crítica de la realidad por contraste, etc. En la literatura religiosa se hallan utopías con frecuencia; casi siempre sobre el rosado más allá: veamos como ejemplo el himno Metodista:

«New arts shall bloom of loftier mould, and mightier music thrill the skies, and every life shall be a song, when all the earth is Paradise" ?.

Y el Católico, escrito por Venancio Fortunato en el siglo vII:

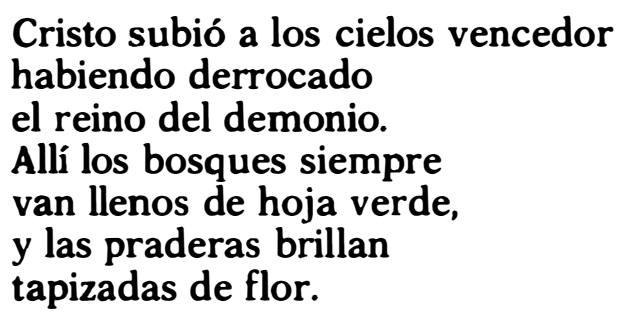

Estos dos ejemplos con 1.200 años de diferencia de edad muestran con toda claridad la esencia de la utopía, de toda utopía: el presupuesto que la realidad presente y actual no es lo que debería ser, lo que podría ser. Por tanto, hay que cambiarla, siguiendo un plan que es utopía en sí mismo. No sería posible la utopía si no hubiera algo de descontento sobre el estado de cosas del presente.

No solamente han sido las religiones las que han hecho florecer utopías desde antiguo, sino también obras literarias como La República y Las Leyes de Platón, el Licurgo de Plutarco y también la historia romana. En las grandes migraciones de pueblos, y en las raíces de importantes sistemas políticos debe haber utopías. El pueblo escogido de la Biblia pasaba el Mar Rojo, huyendo de Egipto, en busca de una tierra que manaba leche y miel; a los americanos del siglo XIX, California y Alaska les atraía

${ }^{5}$ Citado de The Quest for Utopia, an Anthology of Imaginary Societies, de Glen Negley y Max Patrick, New Yor, 1952.

6 Yevgeny Zamyatin, We, traducción de M. Ginsburg, New York, 1987.

7 Tomado de John AdDington Symonds, New and Old; a volume of verse, Boston, 1880, p. 226. 
con promesas de minas llenas de oro. En 1961 Nikita Kruschef, heredero de Marx, promete algo así como una Jauja de bienes de consumo para los rusos de los años 80. Pero ahora llega Gorbachov, y, con enorme sentido de realismo, les dice bien claro al pueblo que Jauja queda todavía muy lejos pero a cambio, les ofrece democracia y libertad: otra utopía. Pero en las utopías, el Estado es el que siempre sale ganando.

Los líderes religiosos y políticos y los intelectuales, tanto artistas como escritores, han sido siempre terreno bien abonado donde crecen las utopías. Don Quijote, como carácter principal de esa inmortal novela no es una excepción a la regla. Pero no es el único personaje que crea y cree en utopías; también Sancho tendrá y creará las suyas. Cuando Cervantes escribía el Quijote, Tomás Campanella estaba componiendo una de las utopías clásicas mejor conocidas, Civitas Solis, la Ciudad del Sol. La escribió en italiano primero en 1602 mientras estaba en la cárcel, condenado a cadena perpetua acusado de sedición contra la corona de España que poseía los territorios del Sur de Italia. Fue aprisionado varias veces por razones políticas, y casi cada vez producía un libro mientras pasaba el tiempo en la sombra. En cuanto a la Ciudad del Sol, no fue hasta 1614 cuando preparó la traducción latina, que vio la primera edición en Frankfurt en $1623^{\circ}$. Sigue la tradición general de las utopías italianas, que se presentan circunscritas a una ciudad. En general imita a Platón y Moro.

Este tiempo de los Siglos XVI y XVII era de gran interés por las utopías en toda Europa. Eran los años en que se presentía el fin inmediato de las estructuras feudales de la sociedad, para dar lugar a nuevos sistemas de poder burgués. Incluso en la geografía geopolítica, el centro inmóvil del sistema solar no era ya la tierra sino el sol. A pesar de la prohibición por el Arzobispo de Toledo en $1583^{\circ}$, se publicó en España en $1592^{10}$ la Utopia de Tomás Moro, justamente cien años después que Colón partiera de Palos de Moguer para encontrar un camino corto y utópico al país de las especias. Cervantes pudo ver y sin duda leer las obras utópicas corrientes de su siglo.

${ }^{8}$ F. Thomae Campanellae, Civitas Solis, Francoforti, 1623.

9 Don Quijote, Cap. XI.

10 En la novela de John Wyndham, The Chrysalids (1955), se trata de una utopía de reconstrucción, después de una supuesta guerra nuclear, que comienza en la esquina de una isla. La función utópica la da el fuerte contenido religioso del grupo que trata de desarrollarse imponiendo un punto de vista puritano en extremo y utópico; hasta el punto de no dudar en sacrificar a otros seres humanos a los que se les imputa desviaciones hereditarias. La novela ha tenido un éxito tan enorme que, desde el año 1955, ha visto nada menos que $42 \mathrm{im}$ presiones. 
Las utopías que encontramos en el Quijote, son de diferentes matices: intelectuales, sociales, de sentidos y sentimientos bucales y hedonísticas, literarias, pastoriles, de Dulcinea y Maritornes, religiosas y otras. La primera mención que hace don Quijote de una utopía social es en el discurso de la edad de oro: "Dichosa edad y signos dichosos aquellos a quien los antiguos pusieron nombre de dorados, y no porque en ellos el oro, que en esta nuestra edad de hierro tanto se estima, se alcanzase en aquella venturosa sin fatiga alguna, sino porque entonces los que en ella vivían ignoraban estas dos palabras de tuyo y mío. Eran en aquella santa edad todas las cosas comunes; a nadie le era necesario para alcanzar su necesario sustento tomar otro trabajo que alzar la mano y alcanzarle de las robustas encinas, que liberalmente les estaban convidando con su dulce y sazonado fruto. Las claras fuentes y corrientes ríos, en magnífica abundancia, sabrosas y transparentes aguas les ofrecían".

El pasaje es bien conocido, y no es necesario citar más extensamente. Esta visión nostálgica de una edad de oro del pasado era tópico corriente en la literatura del Renacimiento. Las fuentes más inmediatas eran Ovidio en las Metamorfosis y Virgilio en la Égloga IV y las Georgicas I. También Fran Antonio de Guevara toca el mismo tema en el Reloj de Príncipes. Pero las últimas raíces de este tema van más atrás aún para anclarse en $L a R e$ pública de Platón, quien aboga por abolir la propiedad privada, al menos para las clases rectoras, y describe en el libro III los distintos tipos de hombres con la metáfora de los metales nobles y sus aleaciones. Naturalmente los nacidos del oro son los mejores, los filósofos. En el libro II de la República cita unos versos de Hesiodo y Homero en que se promete una utopía de bendición para el hombre justo: "Sus encinas estarán cargadas de dulces bellotas, y en la cavidad del tronco le ofrecerán las abejas cera y miel" ${ }^{11}$.

Sería casi imposible determinar quien fue el primero en sembrar las semillas de la edad de oro, pero la fronda que han generado ha sido inmensa: han desbordado a todos los clásicos y se ha adaptado por todas las manifestaciones del saber y cultura humanos. Desde una perspectiva cristiana, la edad de oro se convirtió rápidamente en el Edén o en la comunión de los Santos. En la obra de Tomás Moro, que Cervantes pudo leer y sin duda leyó, se presentan las mismas ideas de propiedad en común, de la nostalgia por volver a esa edad de oro del pasado y de la

11 Don Quijote de la Mancha, Edición de Martín de Riquer, Barcelona, 1962, p. 697. 
presentación de un ser humano virtuoso que vive según la naturaleza, busca la satisfacción y el placer y por esto es mejor hombre. Su visión del hombre y de la vida era no de lo probable, sino de lo imposible.

Tal vez Luciano de Somosota cuenta entre los clásicos que presentan una utopía del modo más gracioso e irónico. En las Saturnales, el poeta escribe una carta llena de quejas al dios Saturno diciendo que «los ricos abundan en oro y plata, vestidos y comida, servidores, vinos finos y joyas, mientras que los pobres pasan hambre al verles comer. No es como antes según dicen los poetas: cuando la tierra producía con abundancia las cosechas al alcance de la gente común sin que tuvieran que arar o sembrar; los ríos fluían vino algunos, otros leche y otros miel. Y aún aseguran que los mismos hombres eran de oro, y que la pobreza no existía. En cambio de nosotros no se podría siquiera decir que somos de plomo, sino de algo más vil aún si lo hubierax. En este tono de intensa ironía sigue por unas páginas hasta que llega la respuesta del dios Saturno diciendo que este deber de establecer igualdad en la distribución de las riquezas no le toca a él sino a Júpiter.

En todas sus versiones, el mito de la edad de oro, tan ardiente y nostálgicamente defendido por don Quijote, miraba hacia la vertiente del pasado, tratando de recordar y revivir. En cambio, las utopías políticas y sociales del siglo XIX miran hacia el futuro, tratan de construir activamente una sociedad mejor; como decía Edward Bellamy "The Golden Age lies before us, and not behind us".

Esta doble vertiente de visión utópica se mantiene en general en toda la novela para los dos personajes: don Quijote mira y revive el pasado y el presente; Sancho, el presente y el futuro. El hidalgo decide hacerse caballero upara el servivio de su república" (frase bien utópica), "deshaciendo todo agravio" con que pudiera topar. Además de las injusticias concretas que tratará de mejorar, don Quijote asume la misión de héroe mítico de eliminar a los gigantes de la faz de la tierra; de ese modo contribuiría a la construcción de una sociedad mejor. El problema era que no había gigantes, sino más bien molinos de trigo y odres de vino. De todas formas utopías a niveles múltiples, pero sobre todo sociales en la primera parte del Quijote, siguen en aumento.

La Ínsula Barataria constituye una de las utopías con más visión de futuro, y, a la vez, más llena de desilusión por la obra no terminada. Es el resultado del marco general negativo o distópico en que se halla la Barataria. Sancho presenta soluciones buenas a todos los problemas que se le presentan, tanto de tipo 
especulativo como práctico. Su gobierno avanza rápidamente hacia el establecimiento político de una república ideal. Pero, ¿es en realidad república o ínsula barataria la de los duques? ¿O será tal vez una gran risotada histórica, con sordina, de las clases sociales poderosas sobre las clases bajas que se toman en serio la oportunidad de cambiar el futuro de la sociedad y sus estructuras? Según Cervantes, no queda bien claro si hay intención utópica en el episodio de la Ínsula. El concepto de isla está dentro del campo de utopías clásicas, en Tomás Moro, Platón, Campanella, Wyndham en The Chrysalids, y otras ${ }^{12}$ : todas son islas, que constituyen, por sólo serlo, un símbolo de utopía. Por lo menos Sancho, en su gobierno, trata de limpiar su ínsula de casas de juego, prostitución, sastres ladrones y médicos crueles. La sociedad de su gobierno debería acercarse lo más posible a una ínsula utópica. Lo único que había contribuido don Quijote a la utopía insular de Sancho, era con los detallados consejos para el bien pensar y actuar de su escudero. Es cierto que Sancho desarrolla todas las actividades de este corto período de tiempo en la villa o pueblo de la isla que le toca gobernar; no dice Cervantes si la así llamada «isla" se reduce a un solo pueblo o ciudad o incluye una zona rural de tierras de labranza, alrededor del centro urbano. Todo queda en la sombra, como lo fue la duración del gobierno sanchezco, que se ocultó tras una serie de influencias provenientes del centro de distopías: el castillo de los duques.

Sin embargo, el campo en que florecen más y con mayor insistencia las utopías es en el de la literatura caballeresca. Ante todo, la misma existencia de don Quijote se debe a la utopización de la función caballeresca: una extrapolación temporal de varios siglos que le facilitaba a don Quijote crear y mantener una utopía ucrónica paralela a su existencia. En este sentido toda la vida de don Quijote no fue más que un intento de utopía creada, vista y descrita en forma de novela por Cervantes. El ejemplo más interesante es el de la cueva de Montesinos. Las circunstancias que han acompañado al Quijote en los tres días anteriores han sido de un clima ideal para germinar utopías: el ambiente mágico de las bodas de Camacho, donde se habían representado las danzas teatrales del Interés, de Cupido, de la Poesía y de la Liberalidad. Luego, de camino, el primo le cuenta unos proyectos de obras literarias utópicas: "Otro libro tengo también, a quien he de llamar Metamorfoseos, o Ovidio español, de invención nueva y rara; porque en él, imitando a Ovidio a lo burlesco, pinto quien

12 Don Quijote de la Mancha, Edición de Martín Riquer, p. 697. 
fue la Giralda de Sevilla y el Ángel de la Madalena, quien el caño de vecinguerra de Córdoba, quienes los Toros de Guisando, la Sierra Morena, etc.". Y luego añade: "Otro libro tengo que le llamo Suplemento a Virgilio Polidoro, que trata de la invención de las cosas, que es de grande erudición y estudion ${ }^{13}$. Con estos antecedentes tan intensamente vividos en su inmediata experiencia, don Quijote desciende a la cueva de Montesinos y comienza a soñar: "Ofrecióseme luego a la vista un real y suntuoso palacio o alcázar, cuyos muros y paredes parecían de transparente y claro cristal fabricados; del cual abriéndose dos grandes puertas, vi que por ellas salía y hacia mí se venía un venerable anciano, vestido con un capuz de bayeta morada, que por el suelo le arrastraba" ${ }^{14}$. El pasaje es bien conocido, y también los personajes que por esa utopía se pasean: Montesinos, Durandarte, Belerma, Merlín y por fin, hasta Dulcinea del Toboso aparece en la procesión de esa utopía literaria.

Muy semejante a esas preciosas páginas sobre la visión de la cueva es el otro pasaje, descrito en forma de distopía, pero con la finalidad última de mantener el plano de utopía literaria en el Quijote: «(...) se arroja en mitad del bullente lago, y cuando no se cata ni se sabe donde ha de parar, se halla entre unos floridos campos, con quien los eliseos no tienen que ver ninguna cosa? Allí le parece que el cielo es más transparente, y que el sol luce con claridad más nueva; ofrécesele a los ojos una apacible floresta de tan verdes y frondosos árboles compuesta, que alegra a la vista su verdura, y entretiene los oídos el dulce y no aprendido canto de los pequeños, infinitos y pintados pajarillos que por los intricados ramos van cruzando" ${ }^{15}$. Sigue el pasaje en largo y tendido párrafo, recordando bien de cerca algunos capítulos de la Ciudad de Dios de San Agustín y del Apocalipsis, especialmente el capítulo 22. Así todas las referencias que hace el Quijote a personajes literarios están situadas en un plano utópico y en un tiempo no-histórico y no-existente. Pero hay también, sembradas a través de toda la obra, una notable cantidad de pequeñas utopías, cortas en duración pero bien significativas, que contribuyen a mantener el total de la narración en un nivel ucrónico utopizado (idealizado que se ha venido llamando), uno de esos momentos de utopía es la representación literaria-teatral del retablo de Maese Pedro. La utopía es creada por la representación en el espíritu de los asistentes; gente de pueblo sencilla y duramente trabajada que hallaba en una tal representación tea-

13 Don Quijote de la Mancha, Edición de Martín de Riquer, p. 697.

14 Don Quijote, Edi., cit., p. 703.

15 Don Quijote, Edic. cit., p. 733. 
tral el transporte de todo su ser, por un tiempo al menos, a un mundo desconocido, de un estado emocional intenso y placentero al que el mismo don Quijote no puede resistir el saltar al ruedo de esa utopía teatral con todo entusiasmo: "viendo y oyendo, pues, tanta morisma y tanto estruendo don Quijote, parecíale ser bien dar ayuda a los que huían, y levantándose en pie, en voz alta dijo: No consentiré yo que en mis días y en mi presencia se le haga superchería a tan famoso caballero y a tan atrevido enamorado como don Gaiferos" ${ }^{16}$. Todos necesitamos de esas limitadas utopías cotidianas que nos ayudan a seguir con relativo optimismo y fe en el futuro de nuestras vidas. Los momentos agradables que nos dará un buen concierto la semana próxima, o la gran satisfacción de saber que por fin se ha conseguido la fusión nuclear a baja temperatura, o tal vez la anticipación en las elecciones del propio partido político o quizás la anticipación de que habrá una buena noche de sexo por delante.

Ejemplos son estos de utopías literarias en el Quijote, aunque no intentamos presentar una lista exhaustiva. La utopía literaria tiene sus raíces en la sociedad, aunque mantiene siempre diferencias fundamentales con la social. La utopía literaria suele ser más auténtica, más lejana y menos accesible, la social es más concreta y pragmática. En ella el Estado suele siempre ganar tiempo, ya que las masas irán mirando el futuro en vez del presente. Mientras se mantengan las utopías tanto sociales, como artísticas, la ciencia, tecnología y arte irán progresando. Hay una relación directa entre la búsqueda de la utopía y el desarrollo social; la utopía, de cualquier clase que sea, debe ir encaminada a dar la mayor felicidad a los habitantes de la misma ${ }^{17}$. Karl Manheim, en los años 30, se preguntaba si se podría seguir viviendo sin utopías. Aunque no se debería alejar la consecución excesivamente por delante y más allá de un horizonte asequible, aunque lejano. En Don Quijote, si de algo pecan, tienden a alejarse demasiado, aunque vuelven a reaparecer para recordarnos su presencia; este vaivén irá oscilando hasta el mismo testamento del Quijote, en que se describe la utopía del buen morir: de edad avanzada, con testamento hecho, en la cama y rodeado de fa-

${ }_{16}$ Don Quijote, Edic. cit., p. 730.

17 De esta afirmación, que parece alejada y metafísica sin embargo, tenemos un magnífico ejemplo histórico aplicado a la unión soviética: durante Stalin y hasta ayer, con Gorbachov, se suprimió activamente el valor moral de la religión en aras de la utopía marxista. El resultado ha sido el que sabemos con certeza histórica: el pueblo ruso ha pasado por encima de la utopía política fabricada por sus líderes y ha mantenido fielmente lo que consideraban moral: su religión, su deseo de libertad y de independencia de opresión. 
miliares y de la religión, sin deber nada a nadie pero continuando el vivir en la memoria de todos, en un rincón, por lo menos, del templo de la Fama. Así termina sus días nuestro hidalgo; y con la realización de la utopía de la buena muerte, termina esta obra literaria, sembradora profusa de utopías a través del pasar de los tiempos. Cervantes parece haber comprendido bien que si el hombre renuncia a toda utopía pierde la voluntad de configurar la historia, y por tanto también la capacidad de entenderla.

Uno de los apartados utópivos en El Quijote, más simpáticos por ser más cercanos a todos, es el de los sentidos: las utopías del comer y beber. Siempre han existido en la historia de la humanidad; y se han expresado a través del arte en formas variadísimas. Mencionemos por vía de ejemplo las kermeses de Brueghel, los bodegones de exquisitos manjares de Zurbarán, Juan Sánchez Cotán o Alejandro de Loarte.

En la historia de la cultura, las utopías sensoriales tienen larga tradición. Ya en Homero hay descripciones de los banquetes que los héroes se daban a veces a las orillas del río Xanto y de los pretendientes en Itaca. Platón expone en El Banquete no solamente la teoría del amor sino también toda la concepción metafísica de su sistema filosófico. En un recorrido por la historia de la literatura mundial, encontraríamos restos de ejemplos de esta utopía, desde las Mil y una Noches hasta la Cena de Baltasar (película Babette's Feast).

Cervantes dedica la descripción de la extraordinaria opulencia de comida preparada para las bodas de Camacho no a este plutócrata que acaba no pudiendo conseguir a Quiteria (y aún menos cenar) sino a Sancho Panza, que constituye el baricentro de la utopía culinaria: «Lo primero que se le ofreció a la vista a Sancho fue, espetado en un asador, de un olmo entero, un entero novillo; y en el fuego donde se había de asar ardía un mediano monte de leña, y seis ollas que alrededor de la hoguera estaban no se habían hecho en la común turquesa de las demás ollas; porque eran seis medias tinajas; que cada una cabía un rastro de carne: así embebían y encerraban en sí carneros enteros, sin echarse de ver, como si fueran palominos; las liebres ya sin pellejo y las gallinas sin pluma que estaban colgadas por los árboles para sepultarlas en las ollas no tenían número; los pájaros y caza de diversos géneros eran infinitos, colgados de los árboles para que al aire se enfriasen.

Contó Sancho más de sesenta zaques de más de a dos arrobas cada uno, y todos llenos, según después pareció, de generosos vinos; así había rimeros de pan blanquísimo, como los suele haber de montones de trigo en las eras; los quesos, puestos como 
ladrillos en rejales, formaban una muralla, y dos calderas de aceite mayores que las de un tinte, sevían de freir cosas de masa que con dos valientes palas las sacaban fritas y las zambullían en otra caldera de preparada miel que allí junto estaba (...) Las especias de diversas suertes no parecían haberlas comprado por libras, sino por arrobas, y todas estaban de manifiesto en una grande arca" ${ }^{18}$.

Las clases bajas y destituidas de la España de aquel tiempo, pasaba, con más frecuencia de lo imaginado en nuestro tiempo, hambre y necesidad. Sancho si no era uno de esos, bien poco le faltaba. Era esa descripción como sería la de una de las mejores tiendas de comestibles del siglo XVII. Toda esa abundancia no se llegó a comer, debido al hecho de que la boda no se realizó, y la mitad de los invitados se fueron antes de comenzar la cena. Era la utopía de comer presentada y descrita para los que necesitaban llenar un estómago medio vacío día tras día. Nada de platos finos, solamente montones abundantes de comida; y esos cocineros no se preocuparon siquiera en presentar un solo plato guisado, con tanta abundancia a su alrededor. Pero Cevantes evitó describir un restaurante, con que habría echado abajo la utopía con gran rapidez y junto con la utopía, todos los que aspiraban a una mejor vida. También los esclavos en la República de Platón, aspiraban a una mejora de posición social, ya que, como argüían, no se conformaban con el papel de estómagos medio satisfechos.

Además de la necesidad de comer que tiene el ser humano (condición de vida a nivel de individuo) hay otro deseo fuerte, cuyo fin teleológico es la continuidad de la especie: el deseo sexual. Esencialmente se trata de una necesidad a nivel social, y por eso la utopía prolifera allí como en campo abonado. Más utopías se habrán fabricado sobre este fundamento que en ningún otro campo de actividad humana. Fantasías eutopizantes de variada duración, cortas, largas, en lugares concretos o puramente imaginarios. En la obra que estudiamos hay algún ejemplo de este tipo en la actuación de don Quijote, ninguna para el caso de Sancho. Analizando a los dos caracteres desde las utopías, de cualquier clase que sean, por las que se ven afectados en toda la obra, se nota que don Quijote se inclina más a las utopías sociales, literarias, artísticas y religiosas. Sancho, en cambio, se interesa más en las eutopías sensoriales, más centradas en el yo que proyectadas hacia los otros. Se podrá argüir que Sancho, al ser casado y con hijos, no se interesaba en el otro sexo, sino

${ }^{18}$ Don Quijote, Edic. cit., p. 680. 
más bien en las riquezas, que le permitían elevar su estado y el de los suyos. Puede ser una explicación de la total asexualidad mostrada por Sancho en la novela. Es cierto también que el escritor de utopías tiene que distinguir lo que es moral de lo que es convencional en una sociedad. Las utopías pueden intentar cambiar lo convencional, pero no deberían tocar lo que es percibido como moral. Tal vez ahí radique la explicación de por qué Sancho no muestra el menor interés en personas del otro sexo. Al hallarse tan apurado para encontrar a Dulcinea, produce un soliloquio de profundo examen y al fin decide crear la distopía de más envergadura de toda la obra: la transmutación de Dulcinea.

Para don Quijote, en cambio, la utopía de los sentidos se le presenta en forma de una moza asturiana, en un camaranchón de la venta. Es Maritornes, que ha sido interceptada por el hidalgo cuando ella iba camino de "refocilarse con el harriero: la cual, en camisa y descalza, cogidos los cabellos en una albanega de fustán, con tácitos y atentados pasos entró en el aposento donde los tres (Sancho, Quijote, harriero) se alojaban, en busca del harriero. Pero, apenas llegó a la puerta, cuando don Quijote la sintió, y, sentándose en la cama, a pesar de sus bizmas con dolor de sus costillas, tendió los brazos para recibir a su hermosa doncella. La asturiana, que, toda recogida y callando, iba con las manos delante, buscando a su querido, topó con los brazos de don Quijote, el cual la asió fuertemente de una muñeca, y tirándola hacia sí, sin que ella osase hablar palabra, la hizo sentar sobre la cama. tentóle luego la camisa, y, aunque ella era de harpillera, a él le pareció ser de finísimo y delgado cendal. Traía en las muñecas unas cuentas de vidrio; pero a él la dieron vislumbres de preciosas perlas orientales, los cabellos, que en alguna manera tiraban a crines, él los marcó por hebras de lucidísimo oro de Arabia, cuyo resplandor al del mesmo sol oscurecía. Y el aliento, que, sin duda alguna olía a ensalada fiambre y trasnochada, a él le pareció que arrojaba de su boca un olor suave y aromático; y finalmente, él la pintó en su imaginación de la misma traza y modo que lo había leído en sus libros de la otra princesa que vino a ver el mal ferido caballero, vencida de sus amores, con todos los adornos que aquí van puestos. Y era tanta la ceguedad (eutopía, diríamos hoy) del pobre hidalgo, que el tacto, ni el aliento, ni otras cosas que traía en sí la buena doncella, no le desengañaban, las cuales pudieran hacer vomitar a otro que no fuera harriero; antes le parecía que tenía entre sus brazos a la diosa de la hermosura. Y, teniéndola bien asida, con 
voz amorosa y baja le comenzó a decir" ${ }^{19}$. Es bien sabido por el texto que en vez de una utopía completa, lo que sobrevino a don Quijote fue uno de los castigos distópicos más crueles.

Con el debido respeto a don Quijote, que ha sufrido ya sus buenos golpes de puño del harriero, queremos presentar inmediatamente después de la eutopización de la asturiana, la actitud de constante utopización respecto de todo lo que tenía que ver con Dulcinea. En general, Dulcinea sufría por parte de don Quijote una transmutación emocional-imaginativa más intensa en cuanto a sus circunstancias que en cuanto a su ser. Sus movimientos, acciones, actitudes y palabras; sitio en donde vivía y actuaba... toda esa dinámica es objeto de atención concreta del Quijote, que lo utopizaba todo con gran pormenor y detalle. En el caso de Dulcinea, la utopización es más sosegada y ajustada a cánones tradicionales de lo que había sido con Maritornes; con la asturiana, don Quijote se halla desprovisto de distancia protectora, en condiciones de tener que actuar deprisa, rodeado de testigos en la oscuridad, lleno de golpes recientes y emplastos que tal vez exacerbaban un tanto su imaginación. Cada vez que habla de Dulcinea, don Quijote utopiza su rango, categoría social, quehaceres, color de pelo y piel, sitio donde habitaba, etc. "Ah mi señora Dulcinea del Toboso, extremo de toda hermosura, fin y remate de la discreción, archivo del mejor donaire, depósito de la honestidad, y, últimamente, idea de todo lo provechoso, honesto y deleitable que hay en el mundo!» ${ }^{20}$

En situar la habitación o vivienda de Dulcinea es donde Cervantes lanza la narración a galope por el camino de la utopía: «Sancho, hijo, guía al palacio de Dulcinea: quizá podrá ser que la hallemos despierta. ¿A qué palacio tengo de guiar, cuerpo de sol, respondió Sancho, que en el que yo vi a su grandeza no era sino casa muy pequeña?" ${ }^{21}$

Abandona el caballero con rapidez el camino antiutópico Sanchezco que le conduce a una humilde "casa muy pequeña", y se refugia en la utopización de las actividades de su dama: "Debía de estar retirada entonces, respondió don Quijote, en algún pequeño aislamiento de su alcázar, solazándose a solas con sus doncellas, como es uso y costumbre de las altas señoras y princesas". Persistiendo el caballero en la búsqueda del alcázar de Dulcinea, se dirige a un edificio que proyectaba una larga sombra en la noche: "Y habiendo andado doscientos pasos, dio con el bulto que hacía la sombra, y vio una gran torre, y luego conoció que

19 Don Quijote, Edic. cit., p. 148.

20 Don Quijote, Edic. cit., p. 602.

21 Don Quijote, Edic. cit., p. 571. 
el tal edificio no era alcázar, sino la iglesia principal del pueblo, y dijo: Con la iglesia hemos dado, Sanchon. Mucho ha dado que hablar esta frase cervantina sobre whaber topado con la iglesia». Ningún comentarista la ha interpretado en el sentido utópico que, a mi parecer, tiene: la idea de Dulcinea y la iglesia son lugares creadores de utopías: uno del mundo temporal de Dulcinea y el amor en la tierra y el otro de la utopía celeste y eterna. Dos puntos de anclaje: el amor y la fe ${ }^{22}$.

La utopización de la vivienda se encuentra en toda la novela: la venta será castillo para el resto de los días de don Quijote; y todo lo que tenga techo de cobijo se decretará palacio. El mismo simple albergue que los árboles ofrecen es levantado al plano de la utopía por el enamorado caballero.

No solamente la vivienda de Dulcinea es utopizada sino también sus acciones vitales todas: cosa corriente en poesía, como lo prueba don Quijote mismo con la cita de la tercera Égloga de Garcilaso y las labores que hacían las ninfas fluviales en sus morados de cristal. El mismo estilo de utopización se halla en el pasaje en que Sancho da cuenta a don Quijote de su embajada al llevar la carta a Dulcinea.

Las expresiones utopizantes de la poesía y religión han sido particularmente importantes y abundantes en la literatura. Las formas de expresión han tomado infinitas variantes, pero en el fondo siempre ha existido el deseo de mejora, sublimación y perfeccionamiento del ser humano, tanto en el plano de la realidad material como a nivel del espíritu. La penitencia del caballero en Sierra Morena va destinada a la mejora espiritual, a pasar el camino ascético de la subida al monte de la perfección. Don Quijote apenas si puede establecerse en la falda de dicho monte cuando ya le sacan de allí bajo pretexto de matar a un gigante, es decir, quitar la imperfección e injusticia de la tierra: una geocatarsis universal, incluido el reino de Micomicón.

La utopía de un mundo sin gigantes, sin la maldad de la que eran portadores como símbolos del mal y de lo malo, se halla difuminada a través de toda la obra de Cervantes. La presencia de esos seres descomunales se hace sentir, con más o menos intensidad e importancia, en toda la novela, sobre todo en la primera parte, donde se mencionan unas cincuenta y cinco veces.

22 Don Quijote, Edic. cit., p, 591. La tradición, bíblica en su raíz, se remonta al Cantar de los Cantares, especialmente en el canto tercero: rojos... como palomos; cabellos... hato de negras cabras montaña abajo; dientes... hato de ovejas; cuello... torre de David; brazos... cilindros de oro y pedreria; piernas... columnas de alabastro; cuerpo alto... palmera y pechos... racimos de dátiles. Basten unos ejemplos, pues todo el libro bíblico está lleno de tales metáforas utópicas. 
En la segunda parte, en cambio, hemos hallado solamente unas treinta y cinco alusiones. La necesidad de una limpieza, violenta aunque sea, del mal y de los malos se presenta con mayor fuerza en la primera parte. Al identificar los molinos de viento con gigantes, don Quijote define claramente la actitud que va a tener, como carácter principal de la novela, ante los gigantes: "La ventura va guiando nuestras cosas mejor de lo que acertáramos a desear; porque ves allí, amigo Sancho Panza, donde se descubren treinta o pocos más desaforados gigantes, con quien pienso hacer batalla y quitarles a todos las vidas, con cuyos despojos comenzaremos a enriquecer; que esta es buena guerra, y es gran servicio de Dios quitar tan mala simiente de sobre la faz de la tierra" ${ }^{23}$. Los gigantes, ya desde lo giganto-maquia de la mitología griega, eran enemigos de los dioses y de los hombres, de todo lo racional y de la virtud. Como semibestias incultas, eran el prototipo de la soberbia y opresión de los débiles ${ }^{24}$. En Cervantes, la influencia más consistente sobre su presentación literaria, de los gigantes, viene de la Biblia. Desde la graciosa historia de su generación en el Génesis, donde se cuenta que tales seres desproporcionados fueron el engendro de algunos ángeles que entraron en deseo de las mujeres humanas y generaron tales monstruos, hijos de una ofensa a Dios. Esta idea predomina en todo Don Quijote; y así, Alonso Quijano se lanza como David contra todo Goliat del mundo, necesitado de purificación y de justicia. Son la parte diabólica de la humanidad que don Quijote tiene que limpiar para crear un mundo ideal de utopía. Es la Biblia una de las fuentes primarias de inspiración ya empezando con Goliat: «El gigante Golias, o Goliat, fue un filisteo a quien el pastor David mató de una gran pedrada, según se cuenta en el libro de los Reyes" ${ }^{25}$.

Además de la Biblia, sin duda que Cervantes halló inspiración en autores como Tomás Fazellus, que escribió De Rebus Siculis Decades Duae, Nunc Primum in Lucem Editae (1558), donde se

${ }^{23}$ Don Quijote, Edic. cit., p. 81.

24 Una viva descripción de esa cruel brutalidad de un gigante, caco, puede verse en el libro VIII de la Eneida, versos 193-199. Ovidio los acusa también de crueles y de ser gente sin ley ninguna. Homero y Horacio se hacen eco de las mismas acusaciones, que se irán transmitiendo a través de innumerables generaciones literarias hasta Cervantes.

${ }^{25}$ En el Viejo Testamento se hallan referencias a la raza gigantesca con notable abundancia. Docenas de citas podrían acumularse, y en la mayoría hay la asociación gigante-soberbia. Puede consultarse LouIS GINZBERG, The Legends of the Jews, Philadelphia, 1947. También el importante artículo de WALTER E. STEPHENS, «De Historia gigantum: Theological Anthropology Before Rabelais», Traditio, vol. XL, 1984, 50 . 
habla del tamaño de algunos supuestos restos de gigantes. Este tema era corriente en la cultura del tiempo de Cervantes y anterior a él; mencionaremos solamente algunos como ejemplo ${ }^{26}$. Ya desde el Medioevo se había heredado en la literatura y en el arte una amplia tradición gigantea. La leyenda de Tristán e Isolda, que data del siglo XII es una colección de mitos celtas adaptados al espíritu caballeresco de aquel siglo: finalmente Tristán vence al gigante irlandés Morolt. En la Historia Turpini se menciona la batalla a muerte entre Rolando y el gigante Ferracuto, la lucha dura dos días y acaba con el malo y malicioso ser ${ }^{27}$. También en la Divina Comedia abundan las menciones de gigantes puestos en condiciones de castigo. La titanomaquia y gigantomaquia con los seres infraterrestres e infernales son el escenario donde se mueven en danza amenazadora todos esos monstruos, espanto de los hombres, que irrumpieron en la imaginación de don Quijote con fuerza avasalladora. Son sus enemigos personales por ser malos y contrarios a la sociedad utópica que trata de establecer en un paso más; don Quijote identifica la destrucción de los gigantes con la utopía religiosa del reino de Dios en la tierra kes gran servicio de Dios quitar tan mala simiente de sobre la faz de la tierra", con frecuencia, en la literatura y arte de la época, se identifica la raza gigantea con la soberbia, y aun con el mismo demonio ${ }^{28}$. Por esta razón don Qui-

${ }^{26}$ Tomás Fazellus (1498-1570), fraile siciliano, describe sobre restos mortales de seres enormes hallados en Sicilia citado por EDWARD J. WOOD, Giants and Dwarfs, London, 1868. También se puede consultar Francisco MArouez Villanueva, Fuentes Literarias Cervantinas, Madrid, 1973. También don Quijote, hablando con el cura y el barbero: «...la Santa Escritura, que no puede faltar un átomo en la verdad, nos muestra que los hubo, contándonos la historia de aquel filisteazo de Golias, que tenía siete codos y medio de altura, que es una desmesurada grandeza. También en la isla de Sicilia se han hallado canillas y espaldas tan grandes que su grandeza manifiesta que fueron gigantes sus dueños, y tan grandes como grandes torresw. Don Quijote, Edic. cit., p. 550; ecos de estas creencias, se hallan diseminados por todos los continentes y culturas, como la así llamada «Danza de los Gigantes" para describir los megalitos de Stonehenge: incluso en los viajes de exploradores por suramérica, hay referencias a gigantes: ver Antonio Pigafetta, Primoviaggio Intorno il Mundo, Cleveland, H. \& C. Co., 1906.

${ }^{27}$ En la edición de Beowulf de C. L. WRENN, London, Harrap, 1973, se describe al gigante Grendel como un engendro del diablo, símbolo de todo lo malo y enemigo mortal de los hombres y de la sociedad. En las leyendas asturianas hay gran abundancia de gigantes, con características típicas de los libros de caballerias. En la obra dramática de Shakespeare, hemos contado más de 40 casos de referencias a gigantes en 14 obras teatrales. No pretendo tener, ni mucho menos, un estudio exhaustivo. Que sepa, no lo hay todavía.

28 En el Evangelio apócrifo de SAN BARTOLOMé, del siglo v, según la edición de Montague Rhodes James, Oxford, 1966, se describe al diablo como un gigante de 1.600 codos de altura y 40 de anchura. Se necesitaban 660 ángeles para sujetarle. 
jote queda tan frustrado cuando el encantador contrario le vuelve los gigantes en molinos de viento upor quitarme la gloria de su vencimiento". Esos gigantes, imaginarios y ya muy ridículos y pasados de época en el tiempo de Cervantes constituían o un excelente puente de interés narrativo, difícil de olvidar para todo escritor cercano a esa época. Quedaba siempre, en el fondo de la cultura transmitida, la referencia a un supuesto origen pecaminoso de tales seres: la unión entre ángeles y hembras humanas. Al entroncar firmemente con la tradición gigantea de la Biblia, la literatura del siglo XVII podía aún hacer referencia aceptable a los gigantes. Este aspecto religioso perdura en tiempo de Cervantes, hasta el punto que en la novela se llega a identificar el vencimiento de los gigantes con el control interior de la soberbia, y la victoria sobre un gigante es el triunfo de la humildad ${ }^{29}$.

No es exclusivo de las utopías del siglo XVII el poner como meta la eliminación de la sociedad de elementos discordantes y malos ${ }^{30}$. En la novela de John Wyndham The Chrysalids, publicada por primera vez en 1955, hay como tema central un grupo social de fanáticos religiosos que intentan repoblar la tierra después de una supuesta guerra nuclear. Debido a la radiación sufrida, hay cambios genéticos y mutaciones que se manifiestan tanto en personas como en cosechas. Si un niño nace con seis dedos en una mano o pie o alguna mutación, por ligera que sea, sus padres tienen que declararlo, y la criatura ha de desaparecer. El hombre tiene que ser una perfecta imitación de Dios, ya que fue creado a su imagen y semejanza. No hay sitio para otra cosa en su sociedad.

En el Quijote hay semejante utopía, expresada en la persecución de los injustos, de los gigantes y otros malandrines y follones. En su aspecto de antigigantismo, esta obra de Cervantes es una artística presentación de un velado puritanismo religioso moral. Desde el comienzo de la novela, los gigantes representan más la fuerza bruta en servicio del mal, para ir pasando, bien

${ }^{29}$ Don Quijote, Edic. cit., p. 82. Esta acción de metamorfosis que debida al sabio Frestón, el mismo que le había robado la biblioteca particular a don Quijote. Estos sabios encantadores, que podían ser benévolos o malévolos, eran una clase especial de entes espirituales, poco definidos en su esencia y sólo presentes en sus operaciones; conveniente invención para el mundo narrativo de los libros de acción caballesca del tiempo anterior a Cervantes. En este mundo de imaginación todavía no controlada por los conocimientos científicos, toda una caterva de seres imaginarios aparecían y desaparecían en la imaginación de las gentes y en las páginas de la literatura de su tiempo.

${ }^{30}$ La Utopía de Tomás Moro, publicada ya por Froben de Basilea en 1518, presenta la misma tendencia purificadora; y la italiana Civitas Solis de Tomás Campanella, publicada en 1623, hace lo mismo. 
gradualmente, a ser sobre todo portadores y representantes de la depravación espiritual y de los pecados capitales ${ }^{31}$.

Esta preocupación, para eliminar la raza gigantea, tiene sus últimas raices en la Biblia y tradición religiosa. No es tan explícita de fondo religioso como otras utopías, como la conversión de Zoraida, la penitencia en Sierra Morena o la procesión de disciplinantes. Los dos últimos casos, se fundan sobre la creencia del cristianismo (católico sobre todo) en el valor de la penitencia personal y social. Por la negación de los propios deseos, aunque se hallen perfectamente dentro de un parámetro aceptable humano, y por el castigo del cuerpo, y del espíritu por la humillación, el hombre contribuye al reestablecimiento de un orden perturbado. La purificación y elevación por la penitencia y la necesidad de practicarla es tan vieja para el cristianismo como Juan Bautista en el desierto ${ }^{32}$. Este punto no era de origen platónico en el cristianismo, la herencia provenía de los ritos de purificación y necesidad de penitencia de las religiones anteriores al cristianismo: judaísmo, mazdaísmo y más atrás. Platón, en cambio, «considera siempre el placer como compañero natural de una vida razonable en cada una de las partes del alma" ${ }^{33}$. Don Quijote en Sierra Morena va a hacer penitencia por imitación y para ganar méritos como caballero andante y para ser forjador de una sociedad utópica en el futuro: "Y una de las cosas en que este caballero mostró su prudencia, valor, valentía, sufrimiento, firmeza y amor fue cuando se retiró, desdeñado de la Señora Oriana, a hacer penitencia en la Peña Pobre, mudado su nombre en el de Beltenebrós, nombre, por cierto, significativo y propio para la vida que él de su voluntad había escogido. Ansí, que me es a mí más fácil imitarle en esto que no en hender gigantes, descabezar serpientes,

${ }^{31}$ La misma onomástica de la caterva indica con frecuencia la degradación moral de esos seres. El prefijo Branda (del italiano Brando, espada) ha dado numerosos nombres, tanto de caballeros como de gigantes, por ej. Brandafuriel, Branda-gedeón, Brandesileo, Brandafiel, Brandalión. etc.; el nombre de gigante Pandafilando de la Fosca vista indica un ser portador de una líbido desaforada en extremo que desea a todos los que ve, con turbia vista y deseo. El gigante Cariculiambro, en cambio, tiene una cara nalgática que causa repulsión al interlocutor al tener que establecer diálogo con una culícara. La giganta Andandona (una de las pocas hembras giganteas), del capítulo 25, 2." parte del Quijote, se describe con detalle en el cap. 65 del Amadis de Gaula, como feísima, como un diablo, enemiga mortal de cristianos a quienes hacia mucho mal.

${ }^{32}$ Don Quijote, Edic. cit., p. 236.

33 Ver G. M. A. Grube, El pensamiento de Platón, Madrid, Gredos, 1984, traducción del inglés «Plato's thought» Methuen, 1970. Según Platón, el placer de los sentidos es de signo positivo, ya que ello indica una mayor y más perfecta compenetración entre los tres niveles del alma y de los sentidos exteriores. 
matar endriagos, desbaratar ejércitos, fracasar armadas y deshacer encantamientos" ${ }^{34}$.

La penitencia de los disciplinantes va encaminada a conseguir que llueva el cielo, se puedan salvar las cosechas de cereales en la Mancha $y$, en consecuencia, pueda el pueblo comer bien durante el resto del año: "Era el caso que aquel año habían las nubes negado su rocío a la tierra, y por todos los lugares de aquella comarca se hacían procesiones, rogativas y disciplinas, pidiendo a Dios abriese las manos de su misericordia y lloviese; y para este efecto la gente de una aldea que allí junto estaba venía en procesión a una devota ermita que en un recuesto de aquel valle había" ${ }^{35}$. Más que utopía de la abundancia se debe describir como esperanza del mero sobrevivir; actitud nada ajena a los campesinos de España en aquel tiempo.

La utopía de la conversión de Zoraida está presentada a un doble nivel: la voz narrativa la describe en primer plano; no hay que olvidar, sin embargo, que Cervantes tenía muy poco margen de libertad en la presentación de utopías religiosas: presentaba como utopía lo que le imponía y dictaba la sociedad donde vivía en su tiempo. Zoraida se convierte al cristianismo, saltando por encima de los deberes filiales más básicos, quebrantando el precepto del respeto debido a los padres, y los lectores de la sociedad de Cervantes (probablemente no la voz narrativa) siguen leyendo con gusto y aplaudiendo con satisfacción desde el seguro trono del cristianismo las acciones de la mora Zoraida ${ }^{36}$. Las utopías suelen llevar acuñado en el reverso de su emblema, su signo de crueldad contra alguna de sus clases sociales; en La República de Platón eran los esclavos, los enemigos y hasta las mismas mujeres, a pesar de la aparente liberalidad platónica respecto de la posibilidad de darles a ellas también la opción de estudios y carrera

Tal vez la utopía más cercana al estado de perfección religiosa es el del perfecto y total conocimiento en el hombre. Conocimiento y religión están relacionados ya en el primer libro de la Biblia: esta fue la tentación de Eva y su pecado: "Lo sabreis todo, sereis como dioses". En la novela de Cervantes aflora también la utopía del saber y conocer sin los límites a que estamos sujetos los hombres. Dos ejemplos sobresalientes haremos notar: el del curioso impertinente y el de la cabeza encantada. La historia cuenta que Anselmo consigue por mujer a Camila, doncella principal florentina. Pronto después del matrimonio su felicidad de recién casado comienza a ofuscarse por una duda torturadora:

34 Don Quijote, Edic. cit., p. 237.

35 Don Quijote, Edic. cit., p. 512.

36 Don Quijote, Edic. cit., pp. 412-429. 
¿hasta qué punto le sería fiel su mujer bajo la presión de fuerte tentación? Este deseo llega pronto al nivel de una obsesión sin límites: quiere saber qué haría Camila sujeta a toda posible circunstancia de presión psicológica. Para este marido, el estado perfecto y utópico del conocimiento se situaría en el plano de una posible solicitación amorosa. No es más que una variación del episodio entre Eva y la serpiente. Lotario acaba por aceptar el papel de demonio para abrir a su amigo las puertas de ese utópico reino del saber. La integridad psicológica de dos personas (mujer y amigo) es sacrificada por el espejismo utópico de un perfecto y total conocedor. La progresión psicológica de todo el plan de Anselmo está narrada en un estilo concéntrico que pronto sitúa en el centro del torbellino a tentador y tentada. Acaban los tres personajes aniquilados por el deseo inmoderado de una imposible utopía del conocimiento absoluto ${ }^{37}$.

El otro ejemplo de interés para este estudio es el de la cabeza encantada. Con aura de misterio la presenta Cervantes: "Levantados los manteles y tomando don Antonio por la mano a don Quijote, se entró con él en un apartado aposento en el cual no había otra cosa de adorno que una mesa, al parecer de jaspe, que sobre un pie de lo mesmo se sostenía, sobre la cual estaba puesta, al modo de las cabezas de los emperadores romanos, de los pechos arriba, una que semejaba ser de bronce" ${ }^{38}$. Esta cabeza (hueca por dentro!) tenía la virtud de responder a toda pregunta que se le hiciera. Es decir, era el instrumento que franqueaba la barrera y límites del no saber. Todos podían hacerle preguntas, y a casi todos respondía. El problema de la cabeza de bronce (que su dueño tenía bien guardada y casi escondida) era que recordaba demasiado al saber del diablo. Las respuestas subian de los sótanos de la casa por tubos invisibles; además, no solía poder predecir el futuro. Así que todo el grupo de la sociedad del sarao en casa de don Antonio fueron haciendo preguntas a la cabeza, tomando turnos. Ese grupo del alto ocio constituia un buen representante social general: todos vamos intentando saber el futuro; y todos fracasamos, lo mismo que ese bronce.

A don Quijote mismo, el deseo de saber no le solía abandonar nunca; por eso iba vendiendo fanegas de tierra, para comprar libros sobre caballeros andantes y aprender cómo se debía comportar imitándoles. Sobre Dulcinea, imagina con frecuencia qué

${ }^{37}$ Don Quijote, Edic. cit., p. 345.

${ }^{38} \mathrm{El}$ intento de la sociedad global (aunque representada por unos pocos curiosos) es el averiguar el futuro. La ciencia moderna trata de hacer algo semejante: anticipar lo porvenir por medio de la mejor comprensión del presente. Don Quijote, Edic. cit., p. 989. 
estará haciendo en ese momento; qué tendrá en sus manos, o qué sirgo andará tramando: "No ha de ser parte la mayor hermosura de la tierra para que yo deje de adorar la que tengo grabada y estampada en la mitad de mi corazón y en lo más escondido de mis entrañas, ora estés, señora mía, transformada en cebolluda labradora, ora en ninfa del dorado Tajo, tejiendo telas de oro y sirgo compuestas, ora te tenga Merlin o Montesinos donde ellos quisieren; que adonde quiera eres mía y adoquiera he sido yo he de ser tuyo" ${ }^{39}$. En el contexto de un amor intenso, crece en razón directa el deseo de saber sobre el ser amado tanto el presente como el futuro: don Quijote refleja esta ley general; pero se encuentra, como todo mortal, con las barras del futuro, siempre móvil hacia adelante, pero siempre implacable en su impenetrabilidad. Y sin embargo, la utopía de poder llegar a leer el futuro sigue para don Quijote y seguirá para nosotros para siempre: más viva y tentadora cuanto más desarrollada esté la técnica de la humanidad. En verdad, muchas de las utopías de hace algunos siglos se van cumpliendo ya; por ejemplo, la del transporte y conquista del espacio. En este campo, tenemos una ilustración muy clara de la esencia de la utopía: lo que se concibe hoy como casi imposible, se conseguirá en el futuro inmediato con el rápido desarrollo de la tecnología. La utopía hecha ya realidad deberá ser expandida rápidamente a nuevos horizontes y proyectada a una zona en que se encuentre segura como utopía durante un buen período de tiempo para el futuro. Así va avanzando la humanidad: con utopías a conseguir por delante y las ya alcanzadas por detrás, hechas historia. Algunas, en este proceso, no se conseguirán nunca. Los episodios del barco encantado y Clavileño son tal vez las utopías más representativas en El Quijote. Respecto al inconveniente de la distancia, afirma Cervantes : "Cuando algún caballero está puesto en algún trabajo, que no puede ser librado de él sino por la mano de otro caballero, puesto que (= aunque) estén distantes el uno del otro dos o tres mil leguas y, aún más, o le arrebatan en una nube o le deparan un barco donde se entre, y en menos de un abrir y cerrar de ojos le llevan, o por los aires, o por la mar, donde quieren y adonde es menester su ayuda; así que, joh Sancho!, este barco está puesto aquí para el mesmo efecto; y esto es tan verdad como es ahora de día; y antes que éste se pase, ata juntos al rucio y a Rocinante, y a la mano de Dios, que nos guie; que no dejaré de embarcarme si me lo pidiesen frailes descalzos" ${ }^{40}$.

${ }^{39}$ Don Quijote, Edic. cit., p. 879.

${ }^{40}$ Don Quijote, Edic. cit., p. 750. 
Para don Quijote, la utopía de abolir las distancias es fundamental para mantener la caballería andante en su esencia y verdadero ser. Es una utopía dentro del estado utópico de la caballería andante. Se trata de conferir a los caballeros andantes la característica angélica o de los espíritus del cambio instantáneo de lugar sin estar sujetos al tiempo ni a los medios de transporte. Es en realidad la expresión más refinada del deseo de volar que el hombre siempre ha sentido. El episodio de Clavileño es el mejor ejemplo de la utopía del transporte rápido. El nombre del caballo es "Clavileño el Aligero, cuyo nombre conviene con el ser de leño, y con la clavija que trae en la frente, y con la ligereza con que camina" ${ }^{41}$, o vuela, mejor dicho. En un símbolo se juntaba la representación de la caballería andante y el medio mecánico de transporte: un gran caballo de madera capaz de llevar a dos pasajeros por los aires, "con sólo torcer esta clavija que sobre el cuello trae puestan. La utopía del transporte rapidísimo, casi no sujeto al tiempo, ha sido una de las más profundas aspiraciones de la humanidad en todos los tiempos. Los dioses de la mitología clásica tenían la capacidad de multiubicación casi instantánea; pero además, a su servicio estaba toda una numerosa turba de transportadores ultra rápidos, como el caballo Pegaso, Mercurio de pies alados o los cupidos al servicio de Venus. En la historia de la literatura universal se ha venido repitiendo la presentación de la utopía transportista ${ }^{42}$. En nuestro tiempo se manifiesta más que nada en la exploración submarina, del espacio o interestelar. La ciencia ficción de hoy es un buen ejemplo de literatura utópica, especialmente preocupada con los transportes utópicos. La obra de Cervantes es una más que cuenta en la tradición histórica de tales utopías.

El género de la novela pastoril estuvo en la mente y deseo creador de Cervantes hasta la muerte; fue la primera obra que salió de su pluma, y pocos días antes de su muerte, al terminar las últimas páginas del Persiles, todavía piensa en ella y promete a don Pedro Fernández de Castro, Conde de Lemos, que "verá el fin de La Galatea, de quien sé está aficionado vuestra excelencia" ${ }^{43}$. Cervantes muere en abril de 1616, y La Galatea se había impreso en 1585: habían pasado 31 años desde la primera edición de La Galatea, don Miguel de Cervantes vuelve a la que-

41 Don Quijote, Edic. cit., p. 825.

42 Battlestar Galactica de GLEN A. LARSON. Valga como ejemplo la nave espacial Integral que se está construyendo en la novela utópica de Zamyatin, We. La utiliza el autor como el instrumento de ficción para la huida del estado opresor presentado en la novela.

${ }^{43}$ Cervantes, Obras Completas, tomo II, p. 1778, Edic. de Aguilar. 
rencia de su primera obra pastoril cuando tenía ya un pie en el estribo. La primera parte de El Quijote se publica en 1604, casi a medio camino entre la fecha de La Galatea y de la muerte del autor. El recuerdo de la literatura pastoril como género literario y a la vez como escape idealizado de una realidad, para Cervantes poco halagadora, de la vida cotidiana. El tema pastoril, como escape literario o de sueño real en la vida del escritor, se presta a la utopización. En la narrativa de El Quijote se pueden mencionar algunos casos donde aflora el tema de la utopía pastoril. Están a nivel literario, naturalmente, pero no deja de traslucirse una cierta nostalgia de utopía por parte del autor: se junta la proyección del deseo de la pluma que escribe y la realidad de los caracteres literarios en las páginas de la obra cervantina. En el caso de Don Quijote, la utopía pastoril sobresale en dos ocasiones especialmente. En los dos casos se trata de una situación de escapismo por parte del personaje de tener que aceptar lo inevitable ante la necesidad o del vencimiento en la playa de Barcelona y en consecuencia el retroceso a un estado de protección y paz total, por lo menos durante un tiempo.

De vuelta de Cataluña al Toboso, don Quijote va pensando en una solución ideal para salvar el ego y su utopía de caballero andante. Se le ocurre una solución magnífica: la vuelta a la vida pastoril, por lo menos por un tiempo. Escape a un mundo percibido como utopía perfecta: «Este es el prado donde topamos a las bizarras pastoras y gallardos pastores que en él querían renovar e imitar a la pastoral Arcadia, pensamiento tan nuevo como discreto, a cuya imitación, si es que a ti te parece bien, querría, oh Sancho, que nos convirtiéramos en pastores, siquier el tiempo que tengo de estar recogido. Yo compraré algunas ovejas, y todas las demás cosas que al pastoral ejercicio son necesarias, y llamándome yo el Pastor Quijotiz y tú el Pastor Pancino, nos andaremos por los montes, por las selvas y por los prados, cantando aquí, endechando allí, bebiendo de los líquidos cristales de las fuentes, o ya de los limpios arroyuelos, o de los caudalosos ríos. Daránnos con abundantísima mano de su dulcísimo fruto las encinas, asiento los troncos de los durísimos alcornoques, sombra los sauces, olor las rosas, alfombras de mil colores matizadas los estendidos prados, aliento el aire claro y puro, luz la luna y las estrellas, a pesar de la escuridad de la noche; gusto el canto, alegría el lloro, Apolo versos, el amor conceptos, con que podremos hacernos eternos y famosos, no sólo en los presentes, sino en los venideros siglos" ${ }^{44}$. Casi todos los

44 Don Quijote, Edic. cit., p. 1025. 
sentidos del cuerpo están representados con la cita, además de la satisfacción de los sentimientos y eterna fama horaciana. Es un mundito aislado, perfecto, ideal para un descanso total y expresión de todo lo bueno existente a que se pueda aspirar. Ahí pensaba don Quijote tomar un refugio, temporal aunque fuera; una utopía cerrada a dos personajes, tal vez, pero situada dentro del género pastoril, utopizante ya de por sí.

El conocido discurso de la edad de oro del capítulo XI tiene lugar también en circunstancias pastoriles; esa vez, con todo, don Quijote está en una situación de superioridad y seguridad en sí mismo. En el capítulo XVII de la segunda parte también se le viene a la mente a don Quijote la utopía del mundo pastoril, pero bajo el signo negativo de la derrota. Esta vez va de vuelta para cumplir las condiciones de retiro forzoso impuestas por su derrota en la playa de Barcelona. Es una evocación de tristeza al pasar por el mismo valle donde viera a los pastores reales en intento de recrear la pastoral Arcadia. Pero esta idea de escapismo utópico se va consolidando en su voluntad a medida que dura el camino de vuelta a la Mancha. De modo que al punto de haber puesto el pie por el dintel de su casa saluda al cura y al bachiller que le están esperando, "Don Quijote, sin guardar términos ni horas, en aquel mismo punto se apartó a solas con el bachiller y el cura, y en breves razones les contó su vencimiento, y la obligación en que había quedado de no salir de su aldea en un año lo cual pensaba guardar al pie de la letra, sin traspasarla en un átomo, bien así como caballero andante, obligado por la puntualidad y orden de la andante caballería, y que tenía pensado de hacerse aquel año pastor y entretenerse en la soledad de los campos, donde a rienda suelta podía dar vado a sus amorosos pensamientos, ejercitándose en el pastoral y virtuoso ejercicio; y que les suplicaba, si no tenían mucho que hacer y no estaban impedidos en negocios más importantes, quisiesen ser de sus compañeros; que él compraría ovejas y ganado suficiente que les diese nombre de pastores; y que les hacía saber que lo más principal de aquel negocio estaba hecho, porque les tenía puestos nombres, que les vendrían como de molde. Díjole el cura que los dijese. Respondió don Quijote que él se había de llamar el Pastor Quijotiz; y el bachiller el pastor Carrascón; el cura el pastor Curambro; y Sancho Panza, el pastor Pancinos ${ }^{45}$. Por fin se ha formalizado, tanto en la mente como en la expresión concreta de don Quijote, el esquema de una utopía completa:la utopía social con diferentes clases de ciudadanos. En este caso

${ }^{45}$ Don Quijote, Edic. cit., p. 1060. 
serán todos pastores a lo pastoril, pero en el ámbito de ese grupo social cada uno tendrá funciones diferentes bien definidas: el bachiller o estamento intelectual, el Quijote o la clase de los guerreros y el cura representante de la clase de los educadores moralistas. Tenemos una réplica, en miniatura, de la República de Platón. Uno tras otro, aunque por detrás del telón del cristianismo, van apareciendo en la escena literaria de esta obra los representantes de las clases que ya se habían paseado por las calles de los atenienses de la República ${ }^{46}$.

No podemos intentar, en el marco de este corto estudio, analizar a fondo todos los ejemplos de utopía sembrados en las páginas de esta novela de Cervantes. Algún caso hay en que se presenta una utopía como marco general, dentro del cual hay algunas otras de parámetros más reducidos, pero no menos significativo. Un ejemplo es el caso de las bodas de Camacho: dentro del marco general de unas bodas de lujo, gran abundancia de manjares, músicos y generosidad por parte del patrón de la fiesta, Camacho, hay pequeñas escenas representativas de miniutopías. Tales son las "muchas y diferentes danzas" que juegan un papel importante, aunque breve, dentro de la acción general; cada una tiene un mensajero: el Interés, Cupido, Poesía o Liberalidad.

Pero Cervantes tiene una visión muy profunda de la vida: sabía que junto al idealismo va paralelo un realismo duro, a menudo cruel. Es el caso de las utopías cervantinas. Las hay en toda la obra, entrecruzadas acá y allá con expresiones de utópico idealismo.

Veamos algunos ejemplos de distopía en el Quijote. Contribuirán a su modo, a aclarar la profundidad de las utopías positivas en la novela: por el valor de contraste del reverso de la medalla.

Miremos con detalle al otro lado de la utopía cervantina en el Quijote. Cervantes presenta la distopía de la novela en dos niveles: el interior de los personajes y en el ambiente que les rodea en su mundo social. Las situaciones distópicas externas resultan mucho más evidentes a primera vista y fáciles de analizar. La distopía interior es sutil y profunda. Ha echado raíces ya en el

${ }^{46}$ Es una cita casi repetida como estribillo de la cita anterior. Muestra la fuerza que la última utopía ejerce en el espíritu de dọn Quijote. El tema de la idea utópica de la vida pastoril dentro de la mente y sentimiento del Quijote como personaje literario, no ha sido estudiado (que yo sepa) hasta ahora. Hay, sin embargo, en la novela, ya desde el comienzo, elementos que apuntan a influencias de las ideas de la narrativa pastoril. Le dedicaremos unas páginas a este punto en el fututo; lo merece. 
episodio de Andrés, en la primera parte, en que se frustra el noble intento de don Quijote de restablecer la justicia en el mundo; para Sancho, hay que buscarla en los diálogos con su mujer y la hija a su vuelta a la aldea, y la presión social lugareña que terminará con la ínsula barataria. Por distopía interna de los personajes entendemos la tensión generada por fuerzas externas que van en contra de los grandes ideales de los caracteres principales. Es una constante erosión de las megalomanías llevada a cabo por la realidad de todos y de cada día. Los diferentes estamentos sociales con que se encuentran don Quijote y Sancho contribuyen a esta erosión de ideales. Hasta a nivel de pura biblioteca se lleva a cabo una atroz distopía con la guerra a los libros del hidalgo. Con los educadores y representantes de la religión no le fue nunca bien a don Quijote hasta hallarse en el lecho de muerte y recibir sus últimas ayudas espirituales. «El eclesiástico, que oyó decir de gigantes, de follones y de encantos, cayó en la cuenta de que aquél debía de ser don Quijote de la Mancha (...) y volviendo la plática a don Quijote, le dijo: Y a vos, alma de cántaro, ¿quién os ha encajado en el cerebro que sois caballero andante y que venceis gigantes y prendeis malandrines? Andad enhorabuena, y en tal se os diga: volveos a vuestra casa, y criad a vuestros hijos, si los teneis, y curad de vuestra hacienda, y dejad de andar vagando por el mundo, papando viento y dando que reir a cuantos os conocen y no conocen". También el barbero, disfrazado de caballero, impone a don Quijote vencido en la playa de Barcelona, semejantes condiciones distópicas. La utopía de don Quijote era la utopía del espíritu, y por ahí tenían que empezar a derrocarle los que querían reducirle al estado de distopía de la vida cabal y cotidiana. En el caso del hidalgo, la utopía coincidía con la locura. Al admitir la curación, en el lecho de muerte, se le va como pájaro volador, todo el castillo de su utopía: "Señores", dijo don Quijote, "vámonos poco a poco, pues ya en los nidos de antaño no hay pájaros hogaño. Yo fui loco y ya soy cuerdo: fui don Quijote de la Mancha y soy agora Alonso Quijano el Buenow. Bueno sí, porque ya ha recobrado la salud mental, pero al precio de la pérdida de sus utopías. Los amigos del pueblo, como el bachiller y el barbero forman, junto con los eclesiásticos, el grupo de persuasión distópica para don Quijote. Quieren reeducar a don Quijote para volverle a la realidad. Ya en la República de Platón la escuela y enseñanza jugaba un papel fundamental para mantener la utopía: aquí se usan también métodos educativos para distopizar al hidalgo.

Los que presentan y representan las distopías más completas y teatrales son los duques, modelos de una clase holgazana y 
prepotente. Pero el caso distópico concreto más fuerte, a nivel de un ciudadano de clase baja, se halla en Andrés, el pastor apaleado por su amo cruel. Al comienzo de la novela, al pobre Andrés le socorre la utopía vibrante, inicial y grandiosa del hidalgo; pero sólo hasta que Rocinante ha traspuesto la loma del encinar: la realidad cruel se vuelve a imponer con rapidez. El juicio social distópico y final tiene lugar en el capítulo 31, donde Andrés le cuenta al caballero: "Mas como vuestra merced le deshonró tan sin propósito, y le dijo tantas villanías, encendiósele la cólera, y como no la pudo vengar en vuestra merced, cuando se vió solo descargó sobre mí el nublado, de modo que me parece que no seré más hombre en toda mi vida" ${ }^{47}$. Don Quijote fue la causa remota de la castración del muchacho; símbolo poderoso de distopía vital. Triste caso para el muchacho, pero arreglo no tiene.

$\mathrm{La}$ anterior, con todo, no pasa de distopía a nivel personal y reducido. La que vamos a mencionar es la distopía social de los duques. Constituye, en nuestra opinión, el contrabalance de más peso del utopismo quijotesco. En el marco general distópico del castillo y tierras de los duques, aparecen acá y allá escenas y pasajes antiutópicos como pequeños cuadros en un tríptico medieval. La misma existencia de los duques, con su vida ociosa, llena de riquezas acumuladas con injusticia y malgastadas con despilfarro, constituía la antítesis de don Quijote y la negación total sus ideales caballerescos. El miniestado de los duques, incluida la ínsula barataria, es lugar del que don Quijote y Sancho quieren pronto ausentarse y apenas lo consiguen. Las acciones repetitivas de captura de los dos personajes, ya famosos por la literatura, son indicadoras de ese mantenido esfuerzo distópico por parte de los duques. Ningún otro episodio en toda la novela presenta un intento tan variado, sutil y pertinaz para despojar a los dos personajes de la obra de sus ideales utópicos. No lo conseguirán a pesar de dueñas, sacos de gatos, clavileños y correos del infieno. La función e intento distópico por parte de los anfitriones ducales está situada a nivel de puro pasatiempo y diversión. Sólo el clérigo que bautiza a don Quijote de «alma de cántaro" quiere en serio volverle a la salud. Los duques intentarán a través de sus opulentas teatralidades, ir desmoronando el ser

${ }^{47}$ Don Quijote, Edic. cit., p. 318. Al terminar este artículo me impuse el deber de leer (de nuevo) el libro de JosÉ Antonio Maravall, Utopía y Contrautopía en el "Quijote", Santiago, 1976. Es obra interesantísima, pero enfocada desde un ángulo diferente del de este artículo.

Otra presentación de una distopía cervantina se puede ver en el Coloquio de los perros, donde Berganza hace una fuerte presentación antiutópica de la sociedad. 
mismo de caballero y escudero, pero con una actitud teleológica de autogratificación. Entre la utopía que don Quijote quiere establecer al estilo de Hythloday y el estilo de vida de los duques, hay un abismo de distancia.

Por otro lado, esta novela tiene una siembra constante de dos semillas: las de las flores de la Edad de Oro, y a la vez la cizaña del mal; de un mal físico y moral que acaba por desmoronar y allanar toda utopía. Un pequeño estudio sobre el mal en Don Quijote, ya lo hemos publicado. Es nuestro intento presentar un breve estudio en que se demuestre que el mal cometido en la novela, va deshaciendo los ideales utopizantes del hidalgo manchego.

ANTONIO MARTí 